\title{
Socio-cultural and Economic Determinants of Maternal Health in Ado-Ekiti, Nigeria
}

\author{
Article by Okpoko, Pius Izundu \\ Department of Public Health, Texila American University, Guyana \\ E-mail: supfaith2000@yahoo.com
}

\begin{abstract}
A major challenge to global health systems is maternal mortality. The vast majority of these deaths are preventable. This research is aimed at investigating sociocultural and economic determinants of maternal health in Ado-Ekiti, south-west geopolitical zone of Nigeria. It was a cross sectional epidemiological study which determined the association between the independent variables (maternal educational status, maternal religion, maternal occupation, decision maker for the commencement of $A N C$, and health care availability/accessibility) and the dependent variable (maternal health as represented by choice of ANC provider). The respondents were 418 females of reproductive age group.

The modal age group was '51 years and above' (24.4\%). The majority of the participants (45.5\%) were married. A total number of 50(12.0\%) respondents had primary education only, $110(26.3 \%)$ secondary education, 130(31.1\%) tertiary, while those without any formal education were 16(3.8\%). There were 112(26.8\%) who did not indicate their educational status and did not give reasons for it. On religion, 216(51.7\%) were self-identified as Christians and 188(45.0\%) as Muslims. Traditional faith constituted 14(3.3\%). Those employed were 178(42.6\%), while 102(24.4\%) were unemployed. Students constituted 82(19.6\%) and Apprentice 56(13.4\%) of the respondents. All the variables tested gave a statistically significant value of $p<0.05$. The selected variables for multivariate logistic regression also gave a statistically significant value of $p<0.05$.

Strategies targeted at improving maternal educational status, making employment available, and encouraging accessibility to health care facilities, may make a significant impact in reducing Maternal Mortality Rates in the studied population.
\end{abstract}

Keywords: Maternal, health, mortality, economic, sociocultural, determinants.

\section{Introduction and background}

A woman's health is very important owing to its direct link to pregnancy, delivery, and the postpartum period. Maternal health encompasses the health care dimensions of family planning, preconception, prenatal, and postnatal care in order to reduce maternal morbidity and mortality (WHO and UNICEF, 2010). The United Nations (UN) has recognized the impact of the burden of maternal deaths, and Goal number 5 of the Millennium Development Goals (MDGs) is to improve maternal health (UN, 2000). Also, Topic 5 of Sustainable Development Goals is to achieve gender equality and empower all women and girls.

The Nigerian government has shown great concern about improving maternal health in the country. Regrettably, there still remains a gross dearth of studies to uncover socio-cultural and economic variables that may predict maternal health. The greatest burden of maternal deaths is borne by the poorest nations of the world where the probability that a 15 year old female will die eventually from pregnancy or delivery is over 200 times greater than in the developed nations (World Health Organization, 2007). Again, a woman dies from complications in childbirth every minute (about 529,000 annually); the vast majority of them are in developing countries (UNICEF, 2010). These burdens were recognized by the United Nations (UN) in the declaration of the Millennium Development Goals (MGDS) in September 2000 (UN, 2000). MDG number 5 focuses on improving maternal health.

The observed poor progress in MDG 5 may not be far from the challenges of the complex nature of maternal mortality (MM). Factors other than medical causes might have been the reason behind each maternal death. These factors tend to operate at individual, family or community level. A clearer understanding of the socio-cultural and economic determinants of maternal health may contribute to 
the design of more dynamic, efficient and comprehensive interventions. Meanwhile, with the ending of MDGs in 2015, and the new Sustainable Development Goals (SDGs), it is hoped that positive impact will further be made to address issues touching maternal health, particularly in settings like Ado-Ekiti in Nigeria, where MMR is still high.

Although the United Nations Population Fund has reported that the number of maternal deaths on a global scale has been reduced by half since 1990, Nigerian situation still reflects a dire case which calls for relief. Nigerian maternal mortality rate has increased from 470 maternal deaths to 630 maternal deaths for every 100,000 live births from 1990 to 2012 (Kucharski, 2013). Majority of the Nigerian states, if not all, are grossly deficient of accurate data and statistics of the prevailing condition. Moreover, detailed studies on maternal health in southwest geopolitical zone of Nigeria are grossly lacking owing to inadequate funding of researches in the related areas by the government. Ado-Ekiti, the Ekiti state capital in Nigeria, is the second poorest state in the Federal Republic of Nigeria. Maternal mortality rate is still high in Ado-Ekiti, therefore the need to embark on a study that will assist policy makers, and those who care to know, in identifying and addressing major determinants of maternal health. The study will lend support to markedly reducing maternal mobility and mortality.

\section{Research aim, objectives and assumptions}

\section{Aim}

This research is aimed at investigating socio-cultural and economic determinants of maternal health in Ado-Ekiti, Nigeria.

\section{Specific objectives}

The specific objectives are:

a. To determine socio-cultural factors as defined by education, religion and cultures that affect maternal health in Ado-Ekiti, southwest geopolitical zone of Nigeria.

b. To determine economic factor as defined by maternal employment that affect maternal health in Ado-Ekiti, Nigeria.

c. To determine the associations between health care availability/accessibility and maternal mortality and morbidity.

\section{Assumptions}

The assumption in this study is that there is an association between socio-cultural and economic factors as defined by education, religion, employment and health care availability/accessibility and maternal mortality and morbidity (the choice of Antenatal care provider and place being an indication of maternal reproductive wellbeing and obstetric outcome). This research has a positivist ideology which brings limitations to conclusions that can be drawn on the possible association between selected variables of determinants of maternal health and maternal mortality and morbidity. There may be other significant determinants that are difficult to measure and quantify which determine maternal health.

\section{Research question}

What socio-cultural and economic determinants are associated with maternal health in Ado-Ekiti, Nigeria?

\section{Methodology}

\section{Research design and approach}

This study was a quantitative study. It is characterized as a cross-sectional method as suggested by Coggon, Barker, and Rose (2003), Trochim and Donnelly (2006), and Bruce, Pope and Stanistreet (2008). Essentially, cross-sectional studies (surveys) are a useful way to gather information on people's knowledge, attitudes, and practices about some health-related issues. They are deemed as a snapshot observational or descriptive epidemiology conducted on representative samples of a population to generate information about the point prevalence estimation of health-related states and conditions to demonstrate associations. A quantitative study of this magnitude assumes positivism. 
Positivism shapes reality to be objective and combines a deductive approach with precise measurement of quantitative data to predict human behaviour (Neuman, 2000). A cross-sectional study was most adequate for the research, and also considering the time frame allotted for the study.

\section{Instrumentation and materials}

A semi-structured, easy-to-read, hard copy survey questionnaire was distributed to participants in Ado-Ekiti, Nigeria. The tool covered the main issues relating to sociocultural and economic aspects of women of reproductive age group. It also touched elements of availability and accessibility of health care facilities. The tool was adapted from related studies done on sociocultural and economic determinants of maternal health and its related maternal mortality and morbidity, though not in AdoEkiti. Additionally, there was a great input from the researcher's knowledge in the field being a medical practitioner who has practised in the geopolitical zone of the country for about two decades. Using SPSS statistical software (version 17.0), the investigator ensured that the reliability of the tool was greater than 0.7. A pilot study was carried out on a portion of the study population which ascertained the easy acceptability of the instrument prior to the main research.

\section{Setting and sample}

The participants sample was drawn from the heterogeneous city of Ado-Ekiti, the capital city of Ekiti state, Nigeria. As of the 2006 Nigerian census estimate, Ekiti state had a population of 2,384,212 of which Ado-Ekiti was 308,621 (Ekitistate.gov.ng, 2015). Female population in Ado-Ekiti was estimated at 196,012 (Nigeria Masterweb, 2007). The population under study was the women of reproductive age group who reside within Ado-Ekiti, Nigeria.

Sample size calculation was done using Cochrane formula $\mathrm{n}=\mathrm{Z}^{2} \mathrm{pq} / \mathrm{d}^{2}$

The estimated sample size was 418 .

\section{The sampling method and sampling frame}

As a cross-sectional study, a non-probability sample of women of reproductive age group was employed to meet the estimated sample size. Therefore, the quantitative findings of this study were based on information collected from the sample population in Ado-Ekiti, Nigeria. Women of reproductive age group in Ado-Ekiti, Nigeria, constituted the sampling frame. There was no previous study of this nature among women of reproductive age group in Ado-Ekiti, Nigeria, to make reference to.

\section{Data collection procedures}

Recruitment of potential participants for this study was done primarily at faith-based organizations (FBO), such as churches and mosques, where majority of participants assembled for worship and social activities. Also, major markets in Ado-Ekiti were used. Initial contacts with leaders of the various groups to explain the purpose and the significance of the research received an overwhelming support. An encouraging welcome was also witnessed among the respondents. This was seemingly rooted on the expectations of the general public to accept measures that would help to address issues of maternal health in developing countries. The investigator explained the study to the various leaders, including the conditions for participating, as well as privacy and confidentiality for data collection. Although the study was free from any serious ethical issues, the researcher painstakingly designed a participant's information sheet that explained the voluntary nature of the study in details, and the anonymity and confidentiality in the study. Necessary translation of the contents of the tools for this research was done to assist the less-learned but with care not to distort or influence the judgment of the participants. The researcher, through trained health workers for data collection, gave the participant's information sheet and questionnaire to eligible and willing participants at the various places designated for data collection. The whole process involved in data collection took about two weeks.

\section{The eligibility criteria}

1. Inclusion criteria: women of reproductive age group who reside in Ado-Ekiti and were present during data collection. 
2. Exclusion criteria: children, men and the elderly were excluded. Also, mentally unstable (insane) females and the seriously ill patients were excluded from the study.

\section{Data analysis}

Data were analyzed using the Statistical Package for Social Sciences (SPSS) software, version 17.0. Socio-demographic data and other core data were demonstrated using easy-to-understand frequency tables.

All survey data were coded and entered for computer analysis using a Microsoft Excel spreadsheet and eventually transferred to SPSS version 17 statistical software. Prior to the analysis, the researcher ensured the cleaning of the data by eliminating unknown, not ascertained, and missing responses from the data set. Again, the missing responses (depending on the nature of the question) were included under 'not sure' or 'others'. In other cases, for example maternal educational status, non-responses were clearly indicated. This pre-analysis data screening was performed prior to the specific objectives/hypotheses-driven analysis. Frequency distribution was used to examine and describe the categorical variables (number and percentages), while the measure of central tendency (mean, standard deviation and $95 \%$. Confidence Interval) was used to describe the continuous variables, such as age.

Pearson Chi square statistics was used to examine the associations between the covariates and the dependent/response variables. The statistics generated the Chi square value, degrees of freedom, and at the p-value 0.05 significance level for the group differences.

The independent variables in this study were maternal educational status, maternal religion, maternal occupation and decision maker for the commencement of ANC. Health care facility availability/accessibility was considered, also. The dependent variable was the 'choice of antenatal care provider'. It is good to note that there were no reliable data on maternal mortality and morbidity in Ado-Ekiti as at the time of this study. Meanwhile, the 'choice of antenatal care provider' stood as a proxy to maternal mortality and morbidity. ANC is a good independent predictor of maternal mortality rates as also suggested by several observational studies (Harrison, 1985; Harrison, 1989; Stokoe, 1991; McClure, 2007; Fotso, Ezeh, and Oronje, 2008; Ameh, 2009).

Unconditional univariable logistic regression was performed for the association between each independent variable and the dependent variable. In the model-building, if a variable was statistically significant at 0.25 (25\% type 1 error tolerance) or biologically and clinical relevant, such as age, it was loaded into the multivariable model. The association between other study covariates and choice of ANC provider was assessed for possible confounding effects prior to entry into the multivariable logistic regression model. This model generated an unadjusted POR, 95\% CI and the p-value.

To adjust for multiple predictors, confounding effects and determine the factual or nonconfounding association between the independent and dependent variables, and other sociodemographic variables simultaneously, unconditional multivariable logistic regression analysis was performed. Stepwise methods, which employed both forward loading and backward elimination procedures, were used to determine the final model.

\section{Ethical issues in this study}

There are no known serious ethical issues in this study. However, the four pillars of medical ethics which are autonomy, nonmaleficence, beneficence, and justice (Grady, 1977) were adhered to. Although the study was free from any serious ethical issues, the researcher painstakingly designed a participant's information sheet that explained the voluntary nature of the study in details, and the anonymity and confidentiality in the study. Worthy of note is that the need to document effectiveness in data collection must be balanced with every effort to ensure the protection and safety of all participants in data collection activities (DHHS/AHRQ/COE, 2009; Ogungbade, 2010). Data collection protocols or procedures in this study included an explicit description of the measures taken to protect the participants involved. The investigator upheld the highest ethical standards when collecting data. Meanwhile, the approval for this research was given by Ekiti State Ministry of Health with the approval number $\mathrm{MOH} / \mathrm{EA} / \mathrm{P} / 01$. 


\section{Results}

A total of 418 questionnaires were distributed and returned. This gave 100\% response rate for the study. There were some questions that were not answered but all the returned questionnaires were analysable.

\section{Socio-demographic distribution of participants}

The socio-demographic distribution of the participants in the study is indicated in the Table below (Table1).

Table 1. Illustrates the socio-demographic distribution of participants

\begin{tabular}{|c|c|c|c|c|c|}
\hline $\begin{array}{l}\text { COVARIA } \\
\text { TE }\end{array}$ & $\begin{array}{l}\text { FREQU } \\
\text { ENCY }\end{array}$ & $\begin{array}{l}\text { PERCEN } \\
\text { TAGE }\end{array}$ & $\begin{array}{l}\text { COVAR } \\
\text { IATE }\end{array}$ & $\begin{array}{l}\text { FREQUE } \\
\text { NCY }\end{array}$ & PERCENTAGE \\
\hline AGE & & & RELIGI & & \\
\hline GROUP & & & $\mathbf{O N}$ & & \\
\hline$<=20$ & 88 & 21.1 & Christian & 216 & 51.7 \\
\hline $21-30$ & 84 & 20.1 & Muslim & 188 & 45.0 \\
\hline $31-40$ & 60 & 14.4 & $\begin{array}{l}\text { Tradition } \\
\text { al faith }\end{array}$ & 14 & 3.3 \\
\hline $41-50$ & 84 & 20.1 & Total & 418 & 100.0 \\
\hline $\begin{array}{l}51 \text { and } \\
\text { above }\end{array}$ & 102 & 24.4 & & & \\
\hline \multirow[t]{2}{*}{ Total } & 418 & 100.0 & \multicolumn{2}{|c|}{$\begin{array}{l}\text { EMPLOYMENT } \\
\text { STATUS }\end{array}$} & \\
\hline & & & $\begin{array}{l}\text { Employe } \\
\text { d }\end{array}$ & 178 & 42.6 \\
\hline MARITAL & TATUS & & $\begin{array}{l}\text { Not } \\
\text { employed }\end{array}$ & 102 & 24.4 \\
\hline Single & 124 & 29.7 & Student & 82 & 19.6 \\
\hline Married & 190 & 45.5 & $\begin{array}{l}\text { Apprenti } \\
\text { ce }\end{array}$ & 56 & 13.4 \\
\hline Separated & 16 & 3.8 & Total & 418 & 100.0 \\
\hline Divorced & 30 & 7.2 & & & \\
\hline Widowed & 58 & 13.9 & & & \\
\hline Total & 418 & 100.0 & & & \\
\hline \multicolumn{3}{|c|}{$\begin{array}{l}\text { PRESENT EDUCATIONAL } \\
\text { STATUS }\end{array}$} & & & \\
\hline Primary & 50 & 12.0 & & & \\
\hline Secondary & 110 & 26.3 & & & \\
\hline Tertiary & 130 & 31.1 & & & \\
\hline Others & 16 & 3.8 & & & \\
\hline No response & 112 & 26.8 & & & \\
\hline Total & 418 & 100.0 & & & \\
\hline
\end{tabular}

All the participants in the study were females of reproductive age group. The modal age group was '51 years and above' (24.4\%). This was closely followed by $41-50$ years $(20.1 \%)$. The majority of the participants $(45.5 \%)$ were married. A total number of $50(12.0 \%)$ respondents only had primary education, $110(26.3 \%)$ secondary education, $130(31.1 \%)$ tertiary, while $16(3.8 \%)$ had no formal education. There were $112(26.8 \%)$ who did not indicate their educational status and did not give reasons for it. The religious affiliation of the participants was assessed with the majority $216(51.7 \%)$ self-identified as Christians and 188(45.0\%) as Muslims, while Traditional faith constitutes 14(3.3\%). Out of all the respondents, those employed $178(42.6 \%)$ were the majority. This was followed by notemployed 102(24.4\%), Students 82(19.6\%) and Apprentice 56(13.4\%). 
DOI: $10.21522 /$ TIJPH.2013.06.01.Art003

ISSN: $2520-3134$

\section{Maternal educational status}

Table 2. The association between maternal educational status and choice of antenatal care provider

Who do you prefer to take care of your antenatal period * present educational status

Present educational status

Primary Secondary Tertiary Others

\begin{tabular}{|c|c|c|c|c|c|c|c|}
\hline \multirow[t]{3}{*}{$\begin{array}{l}\text { Who do you } \\
\text { prefer to take } \\
\text { care of your } \\
\text { antenatal period }\end{array}$} & $\begin{array}{l}\text { Health } \\
\text { care } \\
\text { worker }\end{array}$ & $\begin{array}{l}\% \text { within } \\
\text { present } \\
\text { educationa } \\
\text { 1 status }\end{array}$ & $\begin{array}{l}14 \\
28.0 \\
\%\end{array}$ & $\begin{array}{l}88 \\
80.0 \\
\%\end{array}$ & $\begin{array}{l}130 \\
100.0 \\
\%\end{array}$ & $\begin{array}{l}16 \\
100 . \\
0 \%\end{array}$ & $\begin{array}{c}248 \\
81.0 \%\end{array}$ \\
\hline & $\begin{array}{l}\text { Faith } \\
\text { home } \\
\text { operato } \\
\text { r }\end{array}$ & $\begin{array}{l}\% \text { within } \\
\text { present } \\
\text { educationa } \\
\text { 1 status }\end{array}$ & $\begin{array}{l}22 \\
44.0 \\
\%\end{array}$ & $\begin{array}{l}20 \\
18.2 \\
\%\end{array}$ & $\begin{array}{l}0 \\
.0 \%\end{array}$ & $\begin{array}{l}0 \\
.0 \%\end{array}$ & $\begin{array}{l}42 \\
13.7 \%\end{array}$ \\
\hline & $\begin{array}{l}\text { Traditio } \\
\text { nal } \\
\text { birth } \\
\text { attenda } \\
\text { nt }\end{array}$ & $\begin{array}{l}\% \text { within } \\
\text { present } \\
\text { educationa } \\
\text { l status }\end{array}$ & $\begin{array}{l}14 \\
28.0 \\
\%\end{array}$ & $\begin{array}{l}2 \\
1.8 \%\end{array}$ & $\begin{array}{l}0 \\
.0 \%\end{array}$ & $\begin{array}{l}0 \\
.0 \%\end{array}$ & $\begin{array}{c}16 \\
5.2 \%\end{array}$ \\
\hline
\end{tabular}

Total

$\begin{array}{lllll}50 & 110 & 130 & 16 & 306 \\ 100.0 & 100.0 & 100.0 & 100 . & 100.0 \% \\ \% & \% & \% & 0 \% & \end{array}$

Table 2 presents the results of the association between educational status and choice of antenatal care provider. The Pearson Chi-Square test gave a significant $p$-value $<0.05(\mathrm{p}=0.001)$. In the multivariable logistic regression model which was built through loading and backward elimination after intensive assessment of factors that were statistically significantly associated with choice of ANC provider in the first place and maternal educational status in the second place, there was statistically significant association between choice of ANC provider and maternal educational status.

\section{Maternal religion}

Table 3. The association between maternal religion and choice of antenatal care provider

\begin{tabular}{|c|c|c|c|c|c|c|}
\hline \multicolumn{7}{|c|}{ Who do you prefer to take care of your antenatal period * religion } \\
\hline \multicolumn{7}{|c|}{ Religion } \\
\hline \multirow{6}{*}{$\begin{array}{l}\text { Who do } \\
\text { you prefer } \\
\text { to take } \\
\text { care of } \\
\text { your } \\
\text { Antenatal } \\
\text { period }\end{array}$} & & & $\begin{array}{l}\text { Christ } \\
\text { ian }\end{array}$ & $\begin{array}{l}\text { Musli } \\
\mathrm{m}\end{array}$ & $\begin{array}{l}\text { Tradi } \\
\text { tional } \\
\text { faith }\end{array}$ & Total \\
\hline & Health & & 210 & 148 & & 358 \\
\hline & care & $\%$ & 97.2 & 78.7 & $.0 \%$ & $85.5 \%$ \\
\hline & worker & $\begin{array}{l}\text { within } \\
\text { religion }\end{array}$ & $\%$ & $\%$ & & \\
\hline & Faith & & 4 & 40 & 0 & \\
\hline & $\begin{array}{l}\text { home } \\
\text { operator }\end{array}$ & $\begin{array}{l}\% \\
\text { within }\end{array}$ & $1.9 \%$ & $\begin{array}{l}21.3 \\
\%\end{array}$ & $.0 \%$ & $10.5 \%$ \\
\hline
\end{tabular}


DOI: $10.21522 /$ TIJPH.2013.06.01.Art003

ISSN: $2520-3134$

\begin{tabular}{llllll}
\hline & religion & & & & \\
Tradition & & 2 & 0 & 14 & 16 \\
al birth & $\%$ & $0.9 \%$ & $.0 \%$ & 100.0 & $3.8 \%$ \\
attendant & within & & & $\%$ & \\
& religion & & & &
\end{tabular}

$\begin{array}{llllll}\text { Total } & & 216 & 188 & 14 & 418 \\ & \% & 100.0 & 100.0 & 100.0 & 100.0 \\ & \text { within } & \% & \% & \% & \% \\ & \text { religion } & & & & \end{array}$

Table 3 presents the results of the association between religion and choice of antenatal care provider. The Pearson Chi-Square test gave a statistically significant $\mathrm{p}$-value $<0.05$ ( $\mathrm{p}=0.001)$. 


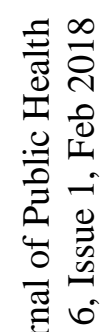

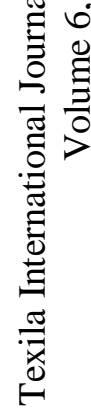

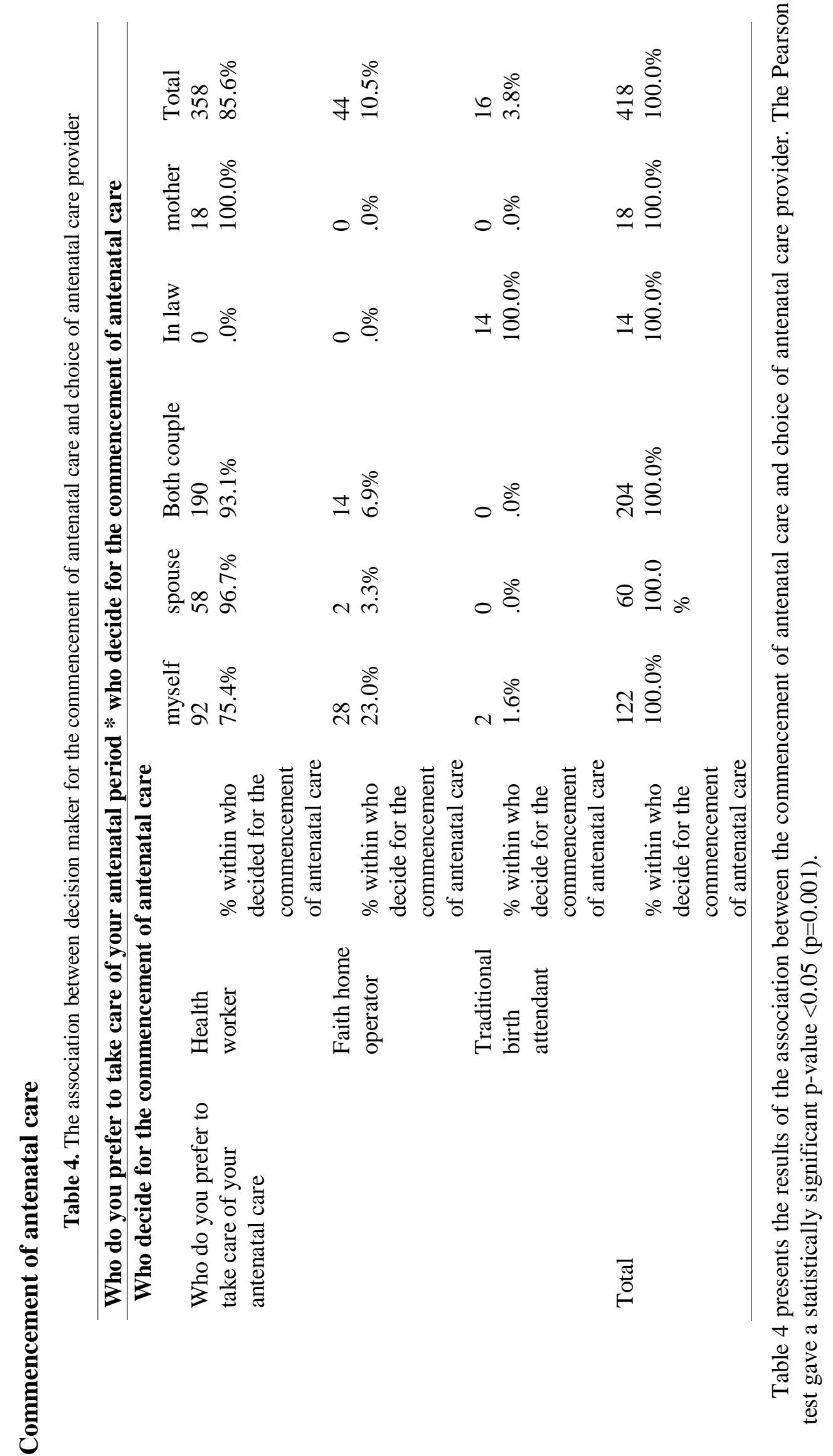




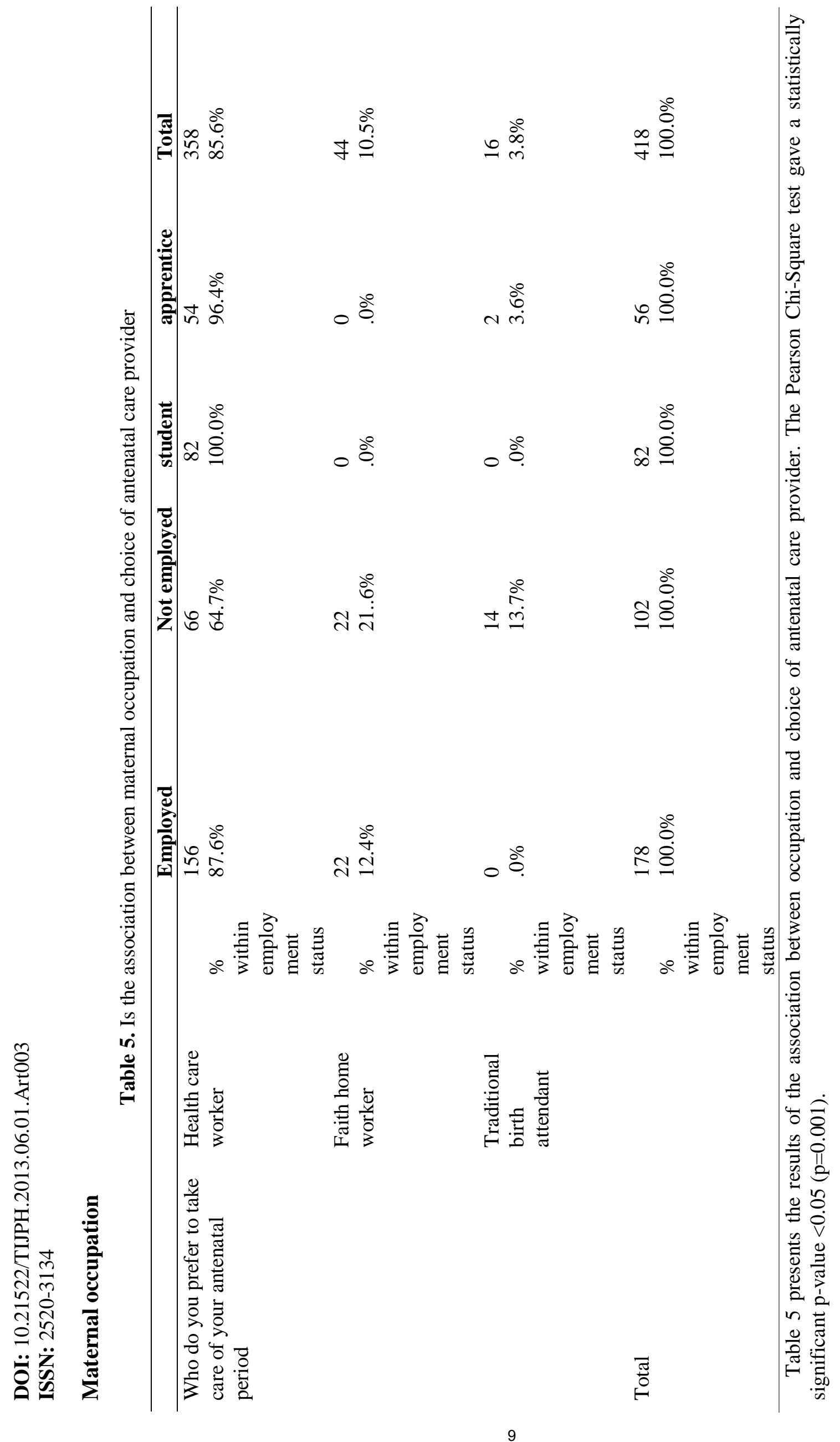




\section{Health care facility availability/accessibility}

There was an additional analysis to determine the association between health care availability/accessibility and choice of antenatal care provider. The factors examined under health care availability/accessibility include lack of money, lack of transport, long distance from health facility and 'health facilities are too expensive'. The p-value was $<0.05$ for all the factors tested. Also, the multivariate regression analysis which was carried out using the aforementioned independent variables revealed statistically significance $\mathrm{p}$-value $<0.05, \mathrm{CI}=1.169-1.718$.

\section{Discussion}

\section{Maternal education}

In this study, maternal education was found to have a statistically significant association with maternal health as indicated by choice of antenatal care provider $(\mathrm{p}<0.05)$. This is similar to associations reported from other studies, though conducted outside Ado-Ekiti, Nigeria. There are several descriptive studies in sub-Saharan Africa that suggested statistically significant association between education, household income, antenatal care (ANC) and maternal health (Abbas and Walker, 1986; Kwast, Rochat, and Kidane-Mariam, 1986; Wong et al., 1987; Harrison, 1988; Kwast and Liff, 1988; Alvarez et al., 2009; Ameh, 2009; McTavish et al., 2010). Karlsen et al. (2011) conducted a cross-sectional study which examined the relationship between maternal education and maternal mortality among women giving birth in health care institutions. They observed that lower levels of maternal education were associated with higher maternal mortality even amongst women who were able to access health facilities providing intrapartum care. On the other hand, Lee et al. (1997) conducted a secondary data analysis on maternal mortality and morbidity and reported a larger negative correlation (-0.82). This could be due to a larger sample size used (78 developing and developed countries) which however represents less than $40 \%$ of the sample. The present study however did an analysis of primary survey data. Worthy of note is the possible mechanisms through which female education and literacy rates operate to reduce MMRs. Ameh (2009) suggested that it may be through increased employment rates resulting in increased incomes and greater access to and utilisation of health care services. Also, increased ability to read, understand and comply with key health messages, increased ability to communicate appropriately with health care providers which also improves their access to health services. Although literacy is a function of education, female education rates in developing countries are low, associated with low primary and secondary education completion rates, there is limited evidence on the most effective level of female education required to positively impact on maternal health outcomes.

From our study, $12.0 \%$ had primary education, $26.3 \%$ secondary education, while $31.1 \%$ had tertiary education. Meanwhile, a combination of 'others' (3.8\%) and those who chose to keep mute (26.8\%) was on a high side. A suspected reason for non-response was shyness emanating from lower levels of educational attainment as a result of early marriage among the studied group. Graham (2016) observed that girls without education are 3 times as likely to marry by 18 years of age as compared with those with a secondary or higher education. Also, over $60 \%$ of 'child brides' in developing countries have had no formal education. Again, with secondary education, females are up to six times less likely to marry as children compared with those having little or no education (Graham, 2016).

\section{Maternal religion}

The test of the association between maternal religion and maternal health as represented by choice of antenatal care provider gave a statistically significant result $(\mathrm{p}=0.001)$. Religion and cultural practices are very important factors that tend to have very strong influence on individual's decision making in most African setting. In Nigeria alone, there are about 400 ethnic groups with their different languages and cultural practices. In settings where there are similar religious beliefs, other factors tend to influence people's health seeking behaviour. Aside from the country-wide differences, religious and cultural diversities exist within the presently known geopolitical zones of the country. That has constituted a wide range of political instability in Nigeria.

The present research finding is in consonant with the study done by Lubbock and Stephenson (2008). They observed that religion has strong influence on culture, and often determines the degree of a woman's accessibility and utilization of health care facilities. Again, Walton and Schbley (2013) 
made a similar observation in rural Bangladesh. They concluded that religious beliefs (and also cultural practices) need be considered when determining future maternal health program development because of their influence on maternal health. Worthy of note is that the major religious groups in our study were Christianity (51.7\%) and Islam (45.0\%). Traditional belief only had 3.3\%. The content of the teachings of the various religious groups need be carefully imbibe into maternal health programs. Basically, none of them completely runs contrary to obvious health needs of the studied reproductive age groups. But it is admittedly known that some traditional practices need be harnessed or modified (in some cases, completely be discouraged) to follow current health practices. For example, the well known but unfavourable female circumcision which predisposes women to difficult labour owing to mutilated female genital organs that healed by second intention.

\section{The decision maker for the commencement of antenatal care}

The present study also found a statistically significant association between the commencement of antenatal care and maternal health with a p-value $<0.05(\mathrm{p}=0.001)$. This aspect of the research has a cultural undertone. In most developing countries, the decision making for the commencement of antenatal care tilts towards men as the head of the family. As earlier observed, family and religion have strong influence on culture, and often determine the level of a woman's accessibility and utilization of health care facilities (Lubbock and Stephenson, 2008; Walton and Schbley, 2013).

\section{Health care availability/accessibility}

The factors examined under health care availability/accessibility include lack of money, lack of transport, long distance from health facility and 'health facilities are too expensive'. The p-value was $<0.05$ for all the factors tested. Also, the multivariate regression analysis which was carried out using the aforementioned independent variables revealed statistically significance $\mathrm{p}$-value $<0.05, \mathrm{CI}=1.169$ - 1.718. The CI indicated statistical stability in the analysis carried out.

Public Health Association of Australia (2012) noted that the vast majority of maternal deaths are preventable. PHAA (2012) observed the 'three delays' that impact on maternal mortality which are: 1) delay envisaged in seeking appropriate medical help for an obstetric emergency due to cost, inability to recognise an emergency, poor education, poor acceptability of the provided services, lack of access to information, and gender inequality. 2) delay owing to distance in reaching an appropriate facility, reasons touching poor infrastructure and lack of transport; and 3) delay in receiving prompt and adequate care when a facility is reached due to shortages in staff, or other amenities like electricity, water and medical supplies (UNFPA, 2011). Importantly, quality of care is of particular significance. Again, to a delay in attaining care, women are not assured of receiving quality care at health facilities. The delivery of poor quality maternity care at health facilities additionally feeds into the first delay as an influential factor on care-seeking behaviour of women (Ith et al., 2012).

\section{Maternal occupation}

The present study tested the association between maternal occupation and choice of antenatal care provider. The Pearson Chi-Square test gave a statistically significant $\mathrm{p}$-value $<0.05(\mathrm{p}=0.001)$. This result may not be unexpected because access to health services in most developing countries is based on out-of-pocket payments for health care services. Therefore, women who are gainfully employed are deemed to have greater resources to access quality health care services. Several descriptive studies have suggested a negative relationship between unemployment and access to maternity care services (Shilling and Lalich, 1984; Harrison, 1985; Kwast et al., 1985; Harrison et al., 1996). Poverty, female employment and income have been shown to be negatively correlated in other analytical studies (Kwast and Liff, 1988; Dao, 2008). The sample size in the Kwast study (1985) was small, while the Dao (2008) study used data from 40 developing countries. It was not clear what criteria were used for the selection of the countries included. These limitations suggest that the results cannot be generalised.

\section{Conclusion}

The independent variables studied (maternal educational status, employment, religion, decision maker for the commencement of antenatal care and health care availability/accessibility) were found to have statistically significant associations with maternal health in the studied population. 
Strategies targeted at improving maternal educational status, creating employment and encouraging accessibility to health care facilities may make a significant impact to reducing MMRs in Ado-Ekiti, Nigeria.

\section{Implications for social change}

The results of this research provided insight into improving maternal health in Ado-Ekiti, Nigeria. Implications for social change include the recognition of the value of maternal education, employment, and cultural factors that have influence on maternal health among the reproductive age group. Providers of services to females of reproductive age group, policy makers, and social advocacy groups that target maternal mortality and morbidity will find the information from this study useful in developing programs directed at improving maternal health.

\section{Recommendations for action/contribution to knowledge}

Maternal education, employment, and cultural factors that have influence on the reproductive age group studied bring insights that provide a broader understanding of maternal health in Ado-Ekiti, southwest geopolitical zone of Nigeria. These insights may help clinicians, public health practitioners and policy-makers improve maternal health, and thereby encouragingly reducing maternal mortality and morbidity.

This study is a foundational study that showcases a basis for further studies in a location where data on the area of research is grossly lacking.

\section{References}

[1]. Abbas, A. A., and Walker, G.J.A. (1986) 'Determinants of the utilization of maternal and child health services in Jordan', International Journal of Epidemiology, 15 (3), pp.404-407.

[2]. Ameh, C. A. (2009) An Analysis of the Recognised Determinants of Maternal Mortality, in sub-Saharan African and South-Asian Countries, [Online]. Available at: University of Liverpool/Laureate Online Education VLE (Accessed: 22 March 2012).

[3]. Bruce, N., Pope, D., and Stanistreet, D. (2008). Quantitative Methods for Health Research: A Practical Interactive Guide to Epidemiology and Statistics, Ed. England: John Wiley \& Sons Ltd.

[4]. Coggon, D., Barker, D., and Rose, G. (2003) Epidemiology for the uninitiated: Case-control and crosssectional studies, 5th ed. London: British Medical Journal Publishing.

[5]. Dao, M. Q. (2008) 'Human capital, poverty, and income distribution in developing countries', Journal of Economic Studies, 35(4), pp.294-303.

[6]. DHHS/AHRQ/COE, Department of Health and Human Services/Agency for Healthcare Research and Quality/Center for Outcomes and Evidence (2009) 'AHRQ developing prospective practice-based comparative effectiveness research clinical registries: Orthopedic devices, drugs, and procedures' (P50), [Online]. Available at: http://grants.nih.gov/grants/guide/rfa-files/RFA- HS-10-008.html (Accessed: 27 July 2015).

[7]. Ekiti state government (2015) 'Population figures of Ekiti state', [Online]. Available at: www.ekitistate.gov.ng (Accessed: 27 July 2015).

[8]. Fotso, J. C., Ezeh, A. and Oronje, R. (2008) 'Provision and use of maternal health services among urban poor women in Kenya: What do we know and what can we do?' Journal of Urban Health, 85(3), pp.428-442.

[9]. Grady, C. (1977) Human immunodeficiency disease: Ethical considerations for clinicians. In V. T. DeVita, Jr, S. Hellman, and S. A. Rosenberg, 4th ed, AIDS: etiology, diagnosis, treatment and prevention. New York: Lippincort-Raven, pp.633-642.

[10]. Graham, C. (2016) 'What is the impact of child marriage?' [Online]. Available at: http://www.girlsnotbrides.org/themes/education/ (Accessed: 2 July 2016).

[11]. Harrison, K. A. (1985) 'Child-bearing, health and social priorities: A survey of 22774 consecutive hospital births in Zaria, northern Nigeria', British Journal of Obstetrics and Gynaecology, 92(5), pp.1-119.

[12]. Harrison, K. A. (1988) 'Maternal mortality--a sharper focus on a major issue of our time', Tropical Journal of Obstetrics and Gynaecology, 1(1).

[13]. Harrison, K. A. (1989) 'Maternal mortality in developing countries', British Journal of Obstetrics and Gynaecology, 96(1),pp.1-3.

[14]. Harrison, K. A., John, C. T., Ojoo, S., and Harry, T. C. (1996) 'Maternal health in developing countries [11]', Lancet, 347(8998), pp.400. 
[15]. Irwin, L. Siddiqi, A. and Hertzman, C. (2007). Early child development: A powerful equalizer. Final Report for the World Health Organisation's Commission on Social Determinants of Health. Geneva: World Health Organisation.

[16]. Ith, P., Dawson, A., Homer, C.S, and Klinken-Whelan, A. (2012) 'Practices of skilled birth attendants during labour, birth and the immediate postpartum period in Cambodia', Midwifery, [Online]. Available at: http://dx.doi.org/10.1016/j.midw.2012.01.010 (Accessed: 30 January 2016).

[17]. Kucharski, M. (2013) 'Maternal mortality in Nigeria: reducing rates through Education', prospect journal.org, [Online]. Available at: http://prospectjournal.org/2013/07/29/maternal-mortality-in-nigeriareducing-rates-through-education (Accessed: 20 August 2015).

[18]. Kwast, B. E., Kidane-Mariam, W., Saed, E. M., and Fowkes, F. G. (1985) 'Epidemiology of maternal mortality in Addis Ababa: A community-based study', Ethiopian Medical Journal, 23(1), pp.7-16.

[19]. Kwast, B. E., and Liff, J. M. (1988) 'Factors associated with maternal mortality in Addis Ababa', Ethiopia. International Journal of Epidemiology, 17 (1), pp. 115-121.

[20]. Kwast, B. E., Rochat, R. W., and Kidane-Mariam, W. (1986) 'Maternal mortality in Addis Ababa, Ethiopia', Studies in Family Planning, 17(6), pp. 288-301.

[21]. Lee, K. S., Park, S. C., Khoshnood, B., Hsieh, H. L., and Mittendorf, R. (1997) 'Human development index as a predictor of infant and maternal mortality rates', Journal of Pediatrics, 131(3),pp.430-433.

[22]. McClure, E. M., Goldenberg, R. L., and Bann, C. M. (2007) 'Maternal mortality, stillbirth and measures of obstetric care in developing and developed countries' International Journal of Gynaecology and Obstetrics, 96(2), pp. 139-146.

[23]. McTavish, S., Moore, S., Harper, S., and Lynch, J. (2010) 'National female literacy, individual socioeconomic status, and maternal health care use in sub-Saharan Africa', Social Science \& Medicine, 71(11), pp. 1958-1963, doi:10.1016/j.socscimed.2010.09.007.

[24]. Neuman, L. (2000) Social Research Methods: Qualitative and Quantitative Approach, 7th Ed. Sydney: Allyn and Bacon.

[25]. Nigeria Masterweb (2015) Nigeria 2006 census figures, [Online]. Available at: www.nigeriamasterweb.com (Accessed: 27 July 2015).

[26]. Ogungbade, G. O. (2010) 'Social Capital Variables as Predictors of HIV Risk-Taking Behaviors among Sub- Saharan African Immigrants in the United States', [Online]. Available at: http://scholarworks. waldenu.edu/cgi/viewcontent.cgi?article=1814\&context=dissertations (Accessed: 27 July 2015).

[27]. Public Health Association of Australia (2012) .Policy-at-a-glance - 'Maternal Mortality, Social Determinants of Health, Millennium Development Goals in Asia Policy', [Online]. Available at: http://www.phaa.net.au/documents/130201_Maternal\%20Mortality,\%20Social\%20Determinants (Accessed: 28 March 2015).

[28]. Shilling, S., and Lalich, N. R. (1984) 'Maternal occupation and industry and the pregnancy outcome of U.S. married women, 1980', Public Health Reports 99(2), pp. 152-161.

[29]. Stokoe, U. (1991) 'Determinants of maternal mortality in the developing world', Australian and New Zealand Journal of Obstetrics and Gynaecology, 31(1), pp. 8-16.

[30]. Trochim, W. M. K. and Donnelly, J. P. (2006). The research methods knowledge base. 3rd ed. New York: Atomic Dog.

[31]. UNFPA (2011) Response to the note verbale, A/61/338: 2 (para. 21).

[32]. United Nations (2000). 'Investing in the health of Africa's mothers', [Online]. Available at: www.un.org/africarenewal/magazine/special-edition-women (Accessed: 26 March 2015).

[33]. United Nations (2000). The millenium declaration: Resolution of the general assembly. New York: United Nations, SS/2.A/Res/SS/2.

[34]. United Nations (2008). The millenium development goals report 2008. New York: United Nations.

[35]. Wong, E. L., Popkin, B. M., Guilkey, D. K., and Akin, J. S. (1987) 'Accessibility, quality of care and prenatal care use in the Philippines', Social Science and Medicine, 24(11),pp.927-944.

[36]. World Health Organisation (2007) Global and regional estimates of the incidence of unsafe abortion and associated mortality in 2003. Geneva: World Health Organisation.

[37]. World Health Organization (2007). Maternal mortality in 2005. Estimates Developed by WHO, UNICEF, UNFPA and the World Bank. Geneva: World Health Organisation.

[38]. World Health Organization and UNICEF (2010). Countdown to 2015 decade report (2000-2010): taking stock of maternal, newborn and child survival (PDF). Geneva: WHO and UNICEF. 